\title{
Dopamine Modulates Cholinergic Cortical Excitability in Alzheimer's Disease Patients
}

\author{
Alessandro Martorana*,1,2, Francesco Mori', Zaira Esposito', Hajime Kusayanagi', Fabrizia Monteleone', \\ Claudia Codecà', Giuseppe Sancesario ${ }^{1,2}$, Giorgio Bernardi ${ }^{2}$ and Giacomo Koch ${ }^{1,2}$ \\ 'Clinica Neurologica, Dipartimento di Neuroscienze, Università di Roma 'Tor Vergata', Roma, Italy and ${ }^{2}$ IRCCS S. Lucia, Ospedale di \\ Neuroriabilitazione, Via Ardeatina, Roma, Italy
}

\begin{abstract}
In Alzheimer's disease (AD) patients dysfunction of cholinergic neurons is considered a typical hallmark, leading to a rationale for the pharmacological treatment in use based on drugs that enhance acetylcholine neurotransmission. However, besides altered acetylcholine transmission, other neurotransmitter systems are involved in cognitive dysfunction leading to dementia. Among others, dopamine seems to be particularly involved in the regulation of cognitive processes, also having functional relationship with acetylcholine. To test whether cholinergic dysfunction can be modified by dopamine, we used short latency afferent inhibition (SLAl) as a neurophysiological tool. First, we tested the function of the cholinergic system in AD patients and in healthy subjects. Then, we tested whether a single L-dopa challenge was able to interfere with this system in both groups. We observed that SLAI was reduced in AD patients, and preserved in normal subjects. L-dopa administration was able to restore SLAl modification only in AD, having no effect in healthy subjects. We conclude that dopamine can modify SLAI in AD, thus confirming the relationship between acetylcholine and dopamine systems. Moreover, it is suggested that together with cholinergic, dopaminergic system alteration is likely to occur in $A D$, also. These alterations might be responsible, at least in part, for the progressive cognitive decline observed in AD patients.

Neuropsychopharmacology (2009) 34, 2323-2328; doi:I0.1038/npp.2009.60; published online 10 June 2009
\end{abstract}

Keywords: transcranial magnetic stimulation; short latency afferent inhibition; L-dopa; acetylcholine; Alzheimer's disease

\section{INTRODUCTION}

The marked dysfunction of cholinergic neurons is considered a typical disease hallmark in Alzheimer's disease (AD), supporting the rationale for current pharmacological treatment based on drugs that enhance acetylcholine neurotransmission. However, besides altered acetylcholine transmission, recent advances evidenced that other neurotransmitter systems might be involved in cognitive dysfunction occurring in AD. Among the others, dopaminergic system may play a relevant role in the mechanisms involved in learning and memory processes, showing strong synaptic interaction with acetylcholine in different brain areas (Blokland, 1995; Brooks, 2006; Cao et al, 2005; Di Cara et al, 2007; Millan et al, 2007). Extrapyramidal signs are sometimes observed in patients suffering from $\mathrm{AD}$, and are related to faster cognitive decline and higher mortality (Rosen and Zubenko, 1991). Impaired dopamine transport in several brain areas has been reported in even in absence

\footnotetext{
* Correspondence: Dr A Martorana, Clinica Neurologica, Dipartimento di Neuroscienze, Università di Roma 'Tor Vergata', via Montpellier, I- 00133, Rome, Italy. Tel.: +003906 72596020; Fax: +003906 72596022, E-mail: martorana@med.uniroma2.it

Received 17 February 2009; revised 5 May 2009; accepted 8 May 2009
}

of extrapyramidal signs (Murray et al, 1995; Pizzolato et al, 1996). Furthermore, dopamine D2 receptors correlation with memory dysfunction was described in AD (Kemppainen et al, 2003). Within these perspectives, we recently showed that in $\mathrm{AD}$ patients the administration of $\mathrm{L}$-dopa determined consistent modifications of cortical activity (Martorana et al, 2008), inducing an increase of short intracortical inhibition (SICI). In that work, we supposed that dopamine could exert its modulatory function influencing, among others, the cortical cholinergic release as well. Here, we aimed to verify this hypothesis by studying the effects of dopamine on the cholinergic cerebral transmission in normal and in $\mathrm{AD}$ patients. To do this, we used a technique that is based on the coupling of TMS with peripheral nerve stimulation. Motor-evoked potentials recorded after TMS of the motor cortex can be suppressed by electrical stimulation of the median nerve if the time between stimulation of the median nerve and that of the motor cortex is $2-8 \mathrm{~ms}$ longer than the time needed by the peripheral nerve afferent input to reach the cortex. This effect is termed as short latency afferent inhibition (SLAI) of the motor cortex, and in general it is considered a measure of inhibitory interactions between afferent input and motor output. It is suggested that cholinergic system modulates these inhibitory interactions. Therefore, SLAI is currently 
considered a non-invasive way to test cholinergic activity in the cerebral cortex in the healthy subjects (Tokimura et al, 2000). On the other hand, other authors suggested that SLAI may depend on the integrity of circuits linking sensory input and motor output rather than on cholinergic function, and thus its modifications may reflect impaired transmission of the sensory afferents (Sailer et al, 2003). Although apparently distant, these two hypotheses might be reasonably reconciled. The fact that cholinergic drugs can modify SLAI values did not necessarily indicate that a cholinergic dysfunction or deficit underlies its modification. Other neurotransmitters, in particular dopamine, are supposed to play a modulatory role on the cholinergic transmission. However, as both the transmitters can serve as neuromodulators, it is conceivable that the functional cholinergic dysfunction may be the consequence of abnormal neuromodulation of dopamine (Orth et al, 2005). Thus, in conditions in which dopamine or acetylcholine system are impaired, SLAI modifications might occur as seen in Parkinson's disease (Sailer et al, 2003, 2007), Tourette's syndrome (Orth et al, 2005), and AD (Di Lazzaro et al, 2002, 2004). Even pharmacological manipulation may unexpectedly induce imbalance in the transmitters release, modifying the electrophysiological findings in course of such pathologies. In fact, as clarified later in the Discussion, the pharmacological manipulation of the dopaminergic system might induce modifications of cortical acetylcholine release acting on nuclei of the non-motor regions of the brain, resulting in the modification of SLAI not observed before (Sailer et al, 2003).

With these premises, here, we tested whether a single dose of orally administered L-dopa can interfere with SLAI test in AD patients compared with healthy controls. We hypothesized that if L-dopa administration could modulate cholinergic activity, in AD patients, changes in the level of SLAI should also be observed more easily.

\section{Subjects}

We examined 10 patients with a diagnosis of probable $A D$ according to the NINCDS-ADRDA criteria (Varma et al, $1999)$ and 10 neurologically healthy age-matched control subjects. The mean (SD) age of the patients was 72.5 (6.1) years, whereas that of controls was 71.7 (4.9) years. All patients underwent a complete clinical investigation, including medical history, neurological examination, minimental state examination (MMSE), a complete blood screening (including, routine exams, thyroid hormones, and level of B12), neuropsychological examination (Pierantozzi et al, 2004), a complete neuropsychiatric evaluation, and neuroimaging consisting of magnetic resonance imaging (1.5 T MRI). Exclusion criteria were the following: patients with isolated deficits and/or unmodified MMSE $(\geqslant 25 / 30)$ on revisit $(6,12,18$ months follow-up), patients with clinically manifest acute stroke in the last 6 months showing an Hachinsky scale $>4$, and a radiological evidence of sub-cortical lesions. None of patients showed pyramidal and/or extrapyramidal signs at the neurological examination. At the time of enrolment, in the 30 days before participating in this study, none of the patients had been treated with drugs that might have modulated cerebral cortex excitability, such as antidepres- sants, or any other neuroactive drugs (ie, benzodiazepines, anti-epileptic drugs, or neuroleptics), even patients assuming drugs like $\alpha$ - or $\beta$-blockers were excluded from that work, as possible interactions with SLAI are not excluded. However, none of the patients has been treated before with cholinesterase inhibitors. The study was performed according to the Declaration of Helsinki and approved by the ethics committee of the Tor Vergata University in Rome. All AD patients showed a cognitive profile consistent with moderate dementia, as assessed by a neuropsychological evaluation, including the MMSE and a standardized neuropsychological battery (Carlesimo et al, 1996). On the MMSE, AD patients scored a mean of 18.23 $( \pm 3.2)$ and Clinical Dementia Rating (CDR) was 1.75 $( \pm 1.6)$. All participants or their legal guardian gave the written informed consent after receiving an extensive disclosure of study. The local ethic committee approved the study procedures.

\section{TMS Procedure}

Magnetic stimulation was performed using a high-power Magstim 200 magnetic stimulator (Magstim Co., Whitland, Dyfed, UK). The magnetic stimuli had a nearly monophasic pulse configuration, with a rise time of $100 \mu \mathrm{s}$, decaying back to zero over $0.8 \mathrm{~ms}$. A figure of eight coils with external loop diameters of $9 \mathrm{~cm}$ was held over the left motor cortex at the optimum scalp position to elicit motor responses in the contralateral first dorsal interosseous (FDI) muscle. The optimal position was marked on the scalp with a felt pen to ensure identical placement of the coil throughout the experiment. The handle of the coil pointed backward and was perpendicular to the presumed direction of the central sulcus, about $45^{\circ}$ to the midsagittal line. The direction of the induced current was from posterior to anterior and was optimal to activate the motor cortex trans-synaptically. Surface muscle responses were obtained through two $9 \mathrm{~mm}$ diameter $\mathrm{Ag}-\mathrm{AgCl}$ electrodes with the active electrode over the motor point of the muscle and the reference on the metacarpophalangeal joint of the index finger. Muscle responses were amplified and filtered (bandwidth 3$3000 \mathrm{~Hz}$ ) by D150 amplifiers (Digitimer, Welwyn Garden City, Hertfordshire, UK). Data were collected on a computer with a sampling rate of $10 \mathrm{kHz}$ per channel and stored for later analysis using a CED 1401 A-D converter (Cambridge Electronic Design, Cambridge, UK). All the AD patients selected were able to understand and carry out the simple task required for this electrophysiological study - that is, to keep fully relaxed. The resting motor threshold (RMT) was defined as the lowest intensity that produced MEPs of $>50 \mu \mathrm{V}$ in at least five out of 10 trials with the muscles relaxed (Rossini et al, 1994). Determination of RMT was done in step width of $1 \%$ of maximal stimulator output (MSO). Short latency inhibition was studied using the technique that has been recently described (Di Lazzaro et al, 2002; Sailer et al, 2003). Conditioning stimuli were single pulses $(200 \mu \mathrm{s})$ of electrical stimulation applied through bipolar electrodes to the right median nerve at the wrist (cathode proximal). The intensity of the conditioning stimulus was set at just over motor threshold for evoking a visible twitch of the thenar muscles. The intensity of the test cortical magnetic stimulus was adjusted to evoke a 
muscle response in relaxed right FDI with an amplitude of $\sim 1 \mathrm{mV}$ peak-to-peak. The conditioning stimulus to the peripheral nerve preceded the magnetic test stimulus by different interstimulus intervals (ISIs). ISIs were determined relative to the latency of the N20 component of the somatosensory evoked potential induced by stimulation of the right median nerve. The active electrode for recording the $\mathrm{N} 20$ potential was attached $3 \mathrm{~cm}$ posterior to $\mathrm{C} 3(10-20$ system) and the reference was $3 \mathrm{~cm}$ posterior to $\mathrm{C} 4$. A total of 500 responses were averaged to identify the latency of the $\mathrm{N} 20$ peak. ISIs from the latency of the N20 plus $2 \mathrm{~ms}$ to the latency of the $\mathrm{N} 20$ plus $8 \mathrm{~ms}$ were investigated in steps of $2 \mathrm{~ms}$. A total of 10 stimuli were delivered at each ISI. The subject was given audiovisual feedback at high gain to assist in maintaining complete relaxation. The inter-trial interval was set at $5 \mathrm{~s}( \pm 10 \%)$, for a total duration of $\sim 5 \mathrm{~min}$. Measurements were made on each individual trial. The mean peak-to-peak amplitude of the conditioned MEP at each ISI was expressed as a percentage of the mean peak-topeak amplitude size of the unconditioned test pulse in that block. To test whether short latency inhibition was sensitive to the changes in L-dopa activity, we examined the motor threshold and the SLAI in 10 patients before and after the administration of a single dose $(125 \mathrm{mg})$ of $\mathrm{L}$-dopa. Measurements were made before and $1 \mathrm{~h}$ after the administration, when L-dopa presented its maximal effects (Martorana et al, 2008).

\section{Statistical Analysis}

The electrophysiological parameters of $\mathrm{AD}$ patients were compared with those of controls by means of repeated measures ANOVA with GROUP (AD vs healthy subjects) as between subjects factor and ISI $(+2,4,6$ and $8 \mathrm{~ms}$ plus the latency of the N20) and TREATMENT (pre- $v s$ postL-DOPA) as within-subject factors. When a significant main effect was reached, $t$-tests with Bonferroni's correction were employed to characterize the different effects of the specific ISIs. For all statistical analyses, a $p$-value of $<0.05$ was considered to be significant. Mauchley's test examined for sphericity. The Greenhouse-Geisser correction was used for non-spherical data.

\section{RESULTS}

None of patients suffered from side effects following assumption of the single dose of L-dopa.

The N20 latency and amplitude were within normal limits in all $\mathrm{AD}$ patients and control subjects and did not differ between the two groups $(20.5 \pm 3.2$ vs $20.8 \pm 2.9)$. The mean (SD) RMT to TMS was significantly lower in AD patients than in controls (45.9\% vs $49.9 \%)$ of MSO; $t=3.14 ; p<0.05$ ) (Figure 1). RMT was not significantly modified by the administration of $\mathrm{L}$-dopa ( $p=0.48$ at paired $t$-test analysis). For unconditioned TS MEPs amplitude pre-and post-L-dopa did not differ being $1.08 \pm 0.33 \mathrm{mV}$ and $1.04 \pm 0.31 \mathrm{mV}$ in $\mathrm{AD}$ and $1.13 \pm 0.25 \mathrm{mV}$ and $1.14 \pm 0.34 \mathrm{mV}$ in controls, respectively. Repeated measures ANOVA performed on SLAI measures showed significant main effects of GROUP $\left(\mathrm{F}=4.26 ; p<0.05 ; \eta^{2}=0.36\right)$ and ISI $\left(\mathrm{F}=7.78 ; p<0.001 ; \eta^{2}\right.$ $=0.61), \quad$ as well-significant GROUP $\times$ TREATMENT

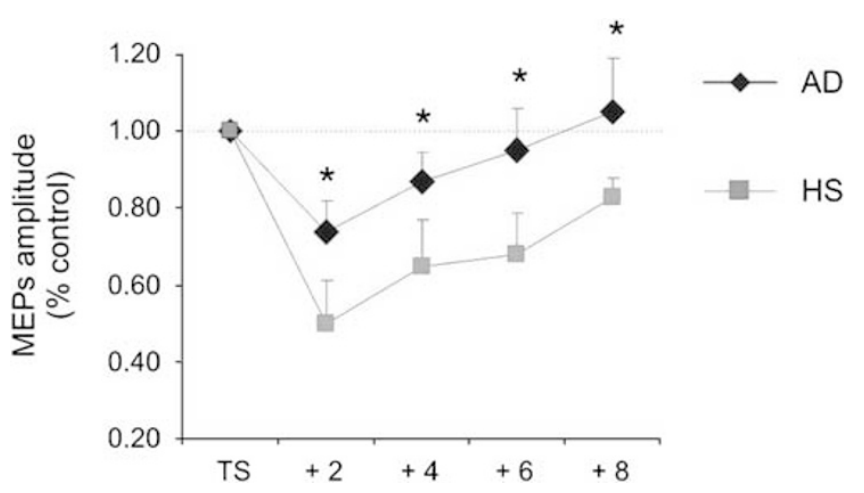

Figure I Short latency afferent inhibition at different interstimulus intervals in $A D$ patients (black diamonds) and control (open squares) subjects. The interval between median nerve stimulation and cortical stimuli was corrected for the latency of the N2O component of the somatosensory evoked potential in each subject (see text). The size of MEPs is expressed as a percentage of the MEP evoked by magnetic stimulation alone. Short latency afferent inhibition was reduced in $A D$ patients at all explored intervals. Error bars indicate standard deviations. $(* P<0.05)$.
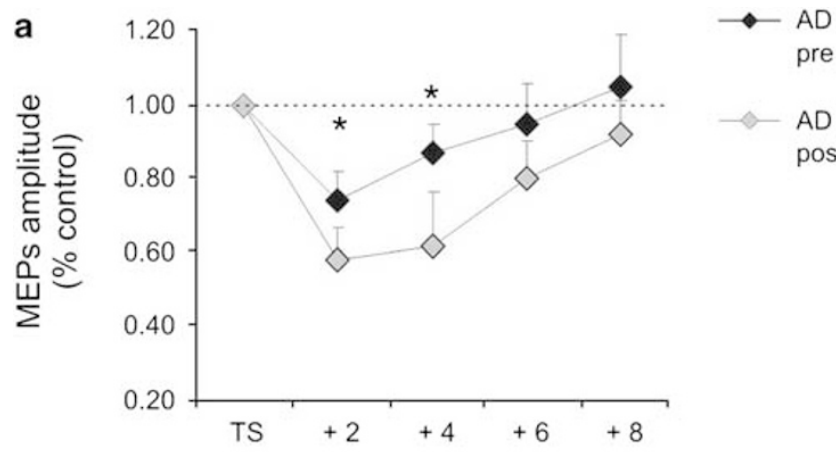

pre

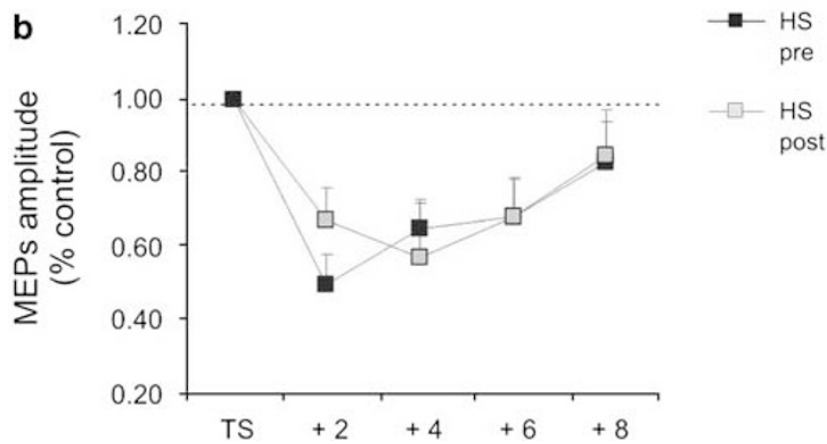

Figure 2 In $A D$ patients, administration of L-dopa was effective in modulating SLAI. (a) SLAI in AD patients was increased after L-dopa administration at $+2 \mathrm{~ms}$ and $+4 \mathrm{~ms}$ ISls. (b) No significant change was observed in healthy subjects. Error bars indicate standard deviations $($ * $p<0.05)$.

$\left(\mathrm{F}=3.96 ; \quad p<0.05 ; \quad \eta^{2}=0.31\right) \quad$ and $\quad$ ISI $\times$ TREATMENT $\left(\mathrm{F}=8.23 ; \quad p<0.001 ; \eta^{2}=0.40\right)$ interactions. The triple interaction GROUP $\times$ ISI $\times$ TREATMENT was not significant. In fact, post hoc analysis showed that before administration of L-dopa the amount of inhibition was significantly smaller in AD patients than in normal controls for all the ISIs tested (all $p<0.05$ ) (Figure 2). The amount of 


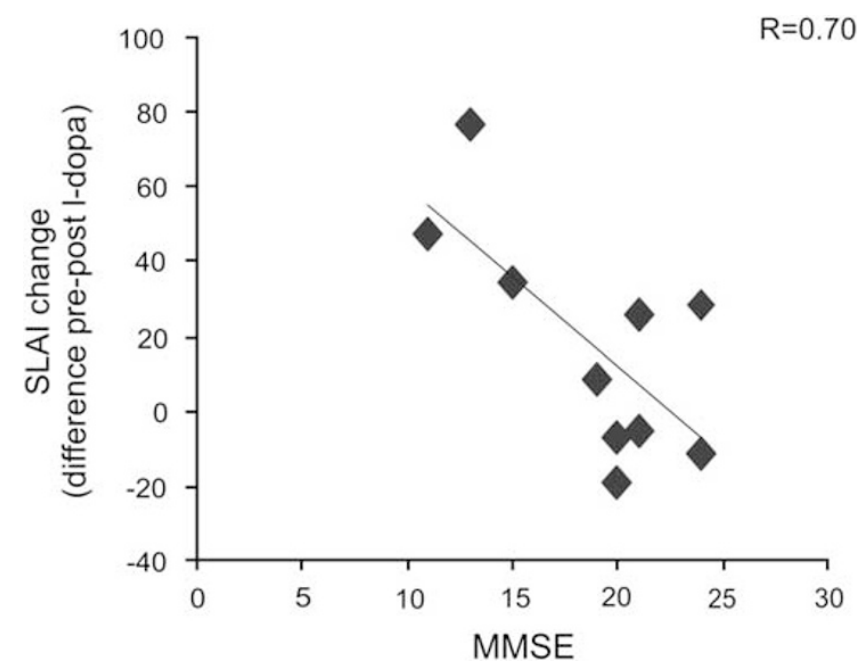

Figure 3 In AD patients, individual changes in SLAI before and after Ldopa administration (measured as the difference of \% SLAl values before and after L-dopa administration) did correlate with scores obtained at MMSE.

inhibition was increased only in $\mathrm{AD}$ patients after L-dopa administration at $+2 \mathrm{~ms}$ and $+4 \mathrm{~ms}$ ISIs (all $p<0.05$ ) (Figure 2a). On the other hand, when the same analysis was performed in a group of healthy controls, no significant difference emerged (Figure $2 b$ ).

Furthermore, in subsequent analysis, we found that in $\mathrm{AD}$ patients the individual amount of increase of SLAI induced by L-dopa (at ISI $=+4 \mathrm{~ms}$, measured as the difference of $\%$ values pre-and post-L-dopa) did correlate with cognitive impairment as assessed by MMSE $(R=0.70 ; p=0.02)$ (Figure 3 and Table 1).

\section{DISCUSSION}

In this work, we confirm that SLAI of the motor cortex is significantly reduced (dis-inhibited) in AD patients compared with age-matched normal subjects (Di Lazzaro et al, 2002). In addition, we observed that SLAI dis-inhibition could be promptly restored by the acute administration of L-dopa to these patients. Our results therefore suggest that dopamine is able to modulate cortical cholinergic function in $\mathrm{AD}$ patients.

In general, SLAI depends on the integrity of corticocortical inhibitory circuits, and is suggested to be modulated at least in part by cholinergic system (Tokimura et al, 2000). In particular, acetylcholine is thought to be involved in the modulation of intracortical circuits mediated by groups of GABAergic interneurons, rather than directly acting on pyramidal cells (Di Lazzaro et al, 2000; 2002, 2004). At this regard, Di Lazzaro et al (Di Lazzaro et al, 2005) showed that different types of benzodiazepines, such as diazepam and lorazepam, resulted in distinct effects on both SICI and SLAI. In particular, diazepam increased both SLAI and SICI, whereas lorazepam reduced SLAI but increased SICI, suggesting that the interactions between cholinergic and GABA-ergic circuits may require the activation of a variety of different receptor subtypes. In this context, we recently described that L-dopa administra-
Table I

\begin{tabular}{lcc}
\hline ISI & $\boldsymbol{t}$ & $\boldsymbol{p}$-values \\
\hline (a) Comparison of SLAI mean values in AD and HS before & L-dopa administration \\
at different ISIs. & \\
$2 \mathrm{~ms}$ & 3.52 & 0.001 \\
$4 \mathrm{~ms}$ & 3.09 & 0.009 \\
$6 \mathrm{~ms}$ & 2.87 & 0.012 \\
$8 \mathrm{~ms}$ & 3.10 & 0.009 \\
& & \\
(b) Comparison of SLAI mean values in AD before and after L-dopa administration \\
at different ISIs & & \\
$2 \mathrm{~ms}$ & 2.88 & 0.009 \\
$4 \mathrm{~ms}$ & 2.81 & 0.010 \\
$6 \mathrm{~ms}$ & 1.82 & 0.102 \\
$8 \mathrm{~ms}$ & 0.62 & 0.554 \\
\hline
\end{tabular}

tion was able to change the excitability of GABAergic intracortical circuits in AD patients (Martorana et al, 2008). The current findings show that dopamine plays a critical role in modulating cortical cholinergic activity also, presumably interacting with such GABAergic intracortical circuits.

Several anatomical (Beckstead et al, 1979; Gaykema and Zaborszky, 1996; Smiley et al, 1999) and pharmacological (Hersi et al, 2000; Millan et al, 2007) studies showed that dopamine and acetylcholine are tightly interconnected, being involved in various cognitive functions, such as memory, attention, and learning (Blokland, 1995; Brooks, 2006, Cao et al, 2005, Di Cara et al, 2007, Millan et al, 2007). It is still unclear, however, whether dopamine modulation of acetylcholine release from cortical neurons occurs through synaptic or non-synaptic (volume transmission) mechanisms or possibly through a combination of both. However, on the anatomical ground the dopaminergic control of cortical acetylcholine release likely occurs at different levels.

Dopamine released from terminals directly in the motor cortex could have favorable effects either acting on intracortical cholinergic interneurons bearing receptors for dopamine (Berlanga et al, 2005), or could act at subcortical level facilitating the glutamatergic excitatory drive from thalamo-cortical pathway, on the classic basalganglia-thalamo-cortical loop (DeLong, 1990). In this view, the thalamo-cortical inputs would in turn excite cortical cholinergic neurons bearing glutamatergic receptors (Conti et al, 1999). Alternatively, dopamine could act through the modulation of the projections originating from the Nucleus Accumbens (NAcc) to the cholinergic basal forebrain neurons (Ingham et al, 1998; Sarter et al, 1999). The NAcc is a subcortical nucleus considered the ventral homolog of caudate-putamen and the NAcc neurons give rise to a massive GABAergic projection to the basal forebrain neurons. Several line of evidence showed that the pharmacological manipulation of accumbal dopamine receptors, can influence the acetylcholine release in cortex. In particular, the accumbal dopamine, D2-like receptor stimulation has a negative effect on the acetylcholine release 
from the basal forebrain cholinergic neurons projecting to the cortex (Del Arco et al, 2007; Brooks et al, 2007), whereas the dopamine D1-like receptor activation has opposite effects (Löffler et al, 2006). The suggested mechanisms, that may be not mutually exclusive, could in turn influence the cortical excitability acting on cortical GABA interneurons, modulating cortical hyperexcitability (Di Lazzaro et al, 2002 and Martorana et al, 2008), therefore, explaining SLAI changes observed in our recordings.

In this perspective, the finding that L-dopa was able to restore SLAI in AD patients may reside in the anatomofunctional modifications induced by the degenerative processes observed in AD. In fact pathological studies showed that in $\mathrm{AD}$, in addition to $\beta$-amyloid and senile plaques deposits, changes in several neurotransmitter systems occur. Together with the cholinergic system, the serotoninergic and noradrenergic systems also seem to be strongly altered (Langlais et al, 1993; Nazarali and Reynolds, 1992; Reinikainen et al, 1988; Zaborszky and Cullinan, 1996). However, the dopaminergic is also implicated (Allard et al, 1994; McNeill et al, 1984). In particular, the reduced levels of dopamine transporters restricted to the NAcc together with altered receptors expression for dopamine recently described (McNeill et al, 1984; Kumar and Patel, 2007), provide sufficient evidence that dopamine content deficit also occurs during the neurodegenerative process of $\mathrm{AD}$. These alterations, in association with the changes because of the progressive neurodegenerative processes (aberrant growth of dendritic trees and amyloid deposit) (Arendt et al, 1995; Preda et al, 2008; Wu et al, 2007) can induce, as a consequence a perturbation in the balance of the other neurotransmitter systems, leading to altered cortical excitability and cognitive decline. In this view, the prompt effect of L-dopa on SLAI has to be interpreted as the result of a momentarily restored transmitter deficiency, leading to restored electrophysiological patterns.

In this view, further studies are needed to verify whether chronic therapy with L-dopa may lead to persistent modifications of cholinergic activity and in which direction. Thus, additional studies with larger samples of patients could determine if the L-dopa effects on cholinergic circuit may be related to disease duration. Finally, it has to be noticed that L-dopa had no effect in control patients. Healthy subjects with a preserved dopaminergic (and cholinergic) system are probably capable of storing additional external loads of L-dopa or dopamine in their terminals, so that significant extra-stimulation of dopamine receptors did not occur.

In conclusion, our results suggest that in $\mathrm{AD}$ dopamine may influence cortical cholinergic activity. Further electrophysiological and pharmacological studies are required to better understand the role exerted by specific dopamine receptors on cholinergic circuits. Moreover, the current findings may imply new strategies of intervention even to ameliorate cognitive disturbances in $\mathrm{AD}$.

\section{DISCOLSURE/CONFLICT OF INTEREST}

The authors declare that, except for income received from the primary employer, no financial support or compensa- tion has been received from any individual or corporate entity over the past 3 years for research or professional service and there are no personal financial holdings that could be perceived as constituting a potential conflict of interest.

\section{REFERENCES}

Allard PO, Rinne J, Marcusson JO (1994). Dopamine uptake sites in Parkinson's disease and in dementia of the Alzheimer type. Brain Res 637: 262-266.

Arendt T, Marcova L, Bigl V, Brückner MK (1995). Dendritic reorganisation in the basal forebrain under degenerative conditions and its defects in Alzheimer's disease. I. Dendritic organisation of the normal human basal forebrain. J Comp Neurol 351: 169-188.

Beckstead RM, Domesick VB, Nauta WJ (1979). Efferent connections of the substantia nigra and ventral tegmental area in the rat. Brain Res 175: 191-217.

Berlanga ML, Simpson TK, Alcantara AA (2005). Dopamine D5 receptor localization on cholinergic neurons of the rat forebrain and diencephalon: a potential neuroanatomical substrate involved in mediating dopaminergic influences on acetylcholine release. J Comp Neurol 492: 34-49.

Blokland A (1995). Acetylcholine: a neurotransmitter for learning and memory? Brain Res Brain Res Rev 21: 285-300.

Brooks DJ (2006). Imaging the role of dopamine in health and disease Parkinson's disease as a lesion model. Wien Klin Wochenschr 118: 570-572.

Brooks JM, Sarter M, Bruno JP (2007). D2-like receptors in nucleus accumbens negatively modulate acetylcholine release in prefrontal cortex. Neuropharmacology 53: 455-463.

Cao YJ, Surowy CS, Puttfarcken PS (2005). Different nicotinic acetylcholine receptor subtypes mediating striatal and prefrontal cortical [3H]dopamine release. Neuropharmacology 48: 72-79.

Carlesimo GA, Caltagirone C, Gainotti G (1996). The mental deterioration battery: normative data, diagnostic reliability and qualitative analyses of cognitive impairment. The Group for the Standardization of the Mental Deterioration Battery. Eur Neurol 36: 378-384.

Conti F, Barbaresi P, Melone M, Ducati A (1999). Neuronal and glial localization of NR1 and NR2A/B subunits of the NMDA receptor in the human cerebral cortex. Cereb Cortex 9: 110-120.

DeLong MR (1990). Primate models of movement disorders of basal ganglia origin. Trends Neurosci 13: 281-285.

Di Cara B, Panayi F, Gobert A, Dekeyne A, Sicard D, De Groote L et al (2007). Activation of dopamine D1 receptors enhances cholinergic transmission and social cognition: a parallel dialysis and behavioural study in rats. Int J Neuropsychopharmacol 10: 383-399.

Del Arco A, Mora F, Mohammed AH, Fuxe K (2007). Stimulation of D2 receptors in the prefrontal cortex reduces PCP-induced hyperactivity, acetylcholine release and dopamine metabolism in the nucleus accumbens. J Neural Transm 114: 185-193.

Di Lazzaro V, Oliviero A, Profice P, Pennisi MA, Di Giovanni S, Zito $\mathrm{G}$ et al (2000). Muscarinic receptor blockade has differential effects on the excitability of intracortical circuits in the human motor cortex. Exp Brain Res 135: 455-461.

Di Lazzaro V, Oliviero A, Tonali PA, Marra C, Daniele A, Profice P et al (2002). Noninvasive in vivo assessment of cholinergic cortical circuits in $\mathrm{AD}$ using transcranial magnetic stimulation. Neurology 13: 392-397.

Di Lazzaro V, Oliviero A, Pilato F, Saturno E, Dileone M, Marra C et al (2004). Motor cortex hyperexcitability to transcranial magnetic stimulation in Alzheimer's disease. J Neurol Neurosurg Psych 75: 555-559. 
Di Lazzaro V, Oliviero A, Pilato F, Saturno E, Dileone M, Marra C et al (2005). Neurophysiological predictors of long term response to AChE inhibitors in AD patients. J Neurol Neurosurg Psych 76: 1064-1069.

Gaykema RP, Zaborszky L (1996). Direct catecholaminergiccholinergic interactions in the basal forebrain. II. Substantia nigra-ventral tegmental area projections to cholinergic neurons. J Comp Neurol 374: 555-577.

Hersi AI, Kitaichi K, Srivastava LK, Gaudreau P, Quirion R (2000). Dopamine D-5 receptor modulates hippocampal acetylcholine release. Brain Res Mol Brain Res 76: 336-340.

Ingham CA, bolam JP, Smith AD (1998). GABA-immunoreactive boutons in the rat basal forebrain: comparison of neurons that project to the neocortex with pallidosubthalamic neurones. J Comp Neurol 273: 263-282.

Kemppainen N, Laine M, Laakso MP, Kaasinen V, Någren K, Vahlberg $\mathrm{T}$ et al (2003). Hippocampal dopamine D2 receptors correlate with memory functions in Alzheimer's disease. Eur $J$ Neurosci 18: 149-154.

Kumar U, Patel SC (2007). Immunohistochemical localization of dopamine receptor subtypes (D1R-D5R) in Alzheimer's disease brain. Brain Res 1131: 187-196.

Langlais PJ, Thal L, Hansen L, Galasko D, Alford M, Masliah E (1993). Neurotransmitters in basal ganglia and cortex of Alzheimer's disease with and without Lewy bodies. Neurology 43: 1927-1934.

Löffler M, Bubl B, Huethe F, Hubbe U, McIntosh JM, Jackisch R et al (2006). Dopamine release in human neocortical slices: characterization of inhibitory autoreceptors and of nicotinic acetylcholine receptor-evoked release. Brain Res Bull 68: 361-373.

Martorana A, Stefani A, Palmieri MG, Esposito Z, Bernardi G, Sancesario G et al (2008). L-: dopa modulates motor cortex excitability in Alzheimer's disease patients. J Neural Transm 115: 1313-1319.

McNeill TH, Koek LL, Haycock JW (1984). The nigrostriatal system and aging. Peptides 5(Suppl 1): 263-268.

Millan MJ, Di Cara B, Dekeyne A, Panayi F, De Groote L, Sicard D et al (2007). Selective blockade of dopamine $\mathrm{D}(3)$ versus $\mathrm{D}(2)$ receptors enhances frontocortical cholinergic transmission and social memory in rats: a parallel neurochemical and behavioural analysis. J Neurochem 100: 1047-1061.

Murray AM, Weihmueller FB, Marshall JF, Hurtig HI, Gottleib GL, Joyce JN (1995). Damage to dopamine systems differs between Parkinson's disease and Alzheimer's disease with parkinsonism. Ann Neurol 37: 300-312.

Nazarali AJ, Reynolds GP (1992). Monoamine neurotransmitters and their metabolites in brain regions in Alzheimer's disease: a postmortem study. Cell Mol Neurobiol 12: 581-587.

Orth M, Amann B, Robertson MM, Rothwell JC (2005). Excitability of motor cortex inhibitory circuits in Tourette syndrome before and after single dose nicotine. Brain 128: 1292-1300.

Pierantozzi M, Panella M, Palmieri MG, Koch G, Giordano A, Marciani MG et al (2004). Different TMS patterns of intracortical inhibition in early onset Alzheimer dementia and frontotemporal dementia. Clin Neurophysiol 115: 2410-2418.

Pizzolato G, Chierichetti F, Fabbri M, Cagnin A, Dam M, Ferlin G et al (1996). Reduced striatal dopamine receptors in Alzheimer's disease: single photon emission tomography study with the D2 tracer [123I]-IBZM. Neurology 47: 1065-1068.

Preda S, Govoni S, Lanni C, Racchi M, Mura E, Grilli M et al (2008). Acute-beta-amyloid administration disrupts the cholinergic control of dopamine release in the nucleus accumbens. Neuropsychopharmacology 33: 1062-1070.

Reinikainen KJ, Paljärvi L, Halonen T, Malminen O, Kosma VM, Laakso $M$ et al (1988). Dopaminergic system and monoamine oxidase-B activity in Alzheimer's disease. Neurobiol Aging 9: 245-252.

Rosen J, Zubenko GS (1991). Emergence of psychosis and depression in the longitudinal evaluation of Alzheimer's disease. Biol Psychiatry 29: 224-232.

Rossini PM, Barker AT, Berardelli A, Caramia MD, Caruso G, Cracco RQ et al (1994). Non-invasive electrical and magnetic stimulation of the brain, spinal cord and roots: basic principles and procedures for routine clinical application. Report of an IFCN committee. Electroencephalogr Clin Neurophysiol 91: 79-92.

Sailer A, Molnar GF, Paradiso G, Gunraj CA, Lang AE, Chen R (2003). Short and long latency afferent inhibition in Parkinson's disease. Brain 126: 1883-1894.

Sailer A, Cunic DI, Paradiso GO, Gunraj CA, Wagle-Shukla A, Moro E et al (2007). Subthalamic nucleus stimulation modulates afferent inhibition in Parkinson disease. Neurology 68: 356-363.

Sarter M, Bruno JP, Turchi J (1999). Basal forebrain afferent projections modulating cortical acetylcholine, attention, and implications for neuropsychiatric disorders. Ann NY Acad Sci 877: $368-382$.

Smiley JF, Subramanian M, Mesulam MM (1999). Monoaminergiccholinergic interactions in the primate basal forebrain. Neuroscience 93: 817-829.

Tokimura H, Di Lazzaro V, Tokimura Y, Oliviero A, Profice P, Insola A et al (2000). Short latency inhibition of human hand motor cortex by somatosensory input from the hand. J Physiol (Lond) 523: 503-513.

Varma AR, Snowden JS, Lloyd JJ, Talbot PR, Mann DM, Neary D (1999). Evaluation of the NINCDS-ADRDA criteria in the differentiation of Alzheimer's disease and frontotemporal dementia. J Neurol Neurosurg Psychiatry 66: 184-188.

$\mathrm{Wu}$ J, Khan GM, Nichols RA (2007). Dopamine release in prefrontal cortex in response to beta-amyloid activation of alpha7 nicotinic receptors. Brain Res 1182-1189.

Zaborszky L, Cullinan WE (1996). Direct catecholaminergiccholinergic interactions in the basal forebrain. I. Dopaminebeta-hydroxylase- and tyrosine hydroxylase input to cholinergic neurons. J Comp Neurol 374: 535-554. 